\title{
Studies on Chitin. IV*. Preparation of Acetylchitin Fibers
}

\author{
Seiichi TOKURA, Norio NISHI, Oyin SOMORIN, ${ }^{* *}$ \\ and Junzo NoGUCHI \\ Department of Polymer Science, Faculty of Science, Hokkaido University, \\ Nishi 8-chome, Kitajujo, Kita-ku; Sapporo 060, Japan.
}

(Received February 29, 1980)

\begin{abstract}
Solutions of variously acetylated chitin in formic acid were prepared by freezing with addition of dicholoroacetic acid or organic solvent, and spun into diisopropyl ether to give acetylchitin fibers. 1.0 Acetylchitin fiber was also obtained by the direct acetylation of chitin fiber in a perchloric acid-acetic anhydride mixture. 1.1 Acetylated chitin fiber showed the maximum tenacity, elongation, and knot strength among the variously acetylated chitin fibers, while a maximum Young's modulus was shown by the 1.6 acetylchitin fiber. Acetylchitin fibers have the advantage of greater tenacity and elongation in comparison with chitin fiber. These advantages contribute to the practical usefulness of chitin in spite of its poor solubility in most solvents and poor reactivity toward chemical reagents. Also the acetylchitin film prepared from formic aciddichloroacetic acid mixture is softer and thus more pleasing to the touch than chitin film.

KEY WORDS Acetylchitin / Acetylchitin Fiber / Chitin Fiber / Direct

Acetylation of Chitin Fiber / Spinning Solution / Formic Acid / Dyeability / Acetylchitin Film /
\end{abstract}

It is known that the properties of cellulose fibers can be improved remarkably by the acetylation. However, the difficulty in dying these fibers through the direct application of dyes has been left unsolved because there are no functional group for staining. On the other hand, chitin is a widespread natural polysaccharide and has a chemical structure similar to cellulose except for the amino-acetyl group attached to the $\mathrm{C}_{2}$ position of D-glucose unit and is therefore expected to have better dyeability. There is also the possibility that acetylchitin fiber may be better than cellulose acetate fibers. The chitin fibers in this work were obtained from chitin viscose ${ }^{1}$ or a chitin-formic acid solution ${ }^{2}$ using various coagulation systems. The chitin fibers showed a higher dyeability when subjected to direct dyes than rayon

* A part of this work was presented at the 1st International Conference on Chitin/Chitosan, 1977, April, Boston, U.S.A. This work has been supported by a Grant-in Aid for Scientific Research from the Ministry of Education, Science and Culture, Japan.

** Senior Research Fellow of Japan Society for the Promotion of Science, 1977 and 1978 from the Chemistry Department, University of Lagos, Lagos, Nigeria. fibers, ${ }^{3}$ although chitin fibers had rather poor tenacity and knot strength.

In this paper, the preparation of variously acetylated chitin fibers from acetylchitin prepared according to the procedure of Nishi et al. ${ }^{4}$ is reported and a comparison of the properties of these fibers with those of acetate fibers is made and discussed.

\section{EXPERIMENTAL}

\section{Chitin}

Chitin powder ( $30-45$ mesh) from Alaska King Crab shell was supplied kindly from Kyowa Yushi Co. Ltd.

\section{Acetylchitin}

The acetylation of chitin was carried out by the method in our previous paper. ${ }^{4}$ The degree of acetylation was estimated by elemental analysis using Yanagimoto CHN Corder MT-2.

\section{Preparation of Acetylchitin Solution and Spinning} Acetylchitin was suspended in $99 \%$ formic acid at 
room temperature. The resulting swollen acetylchitin was frozen at $-20^{\circ} \mathrm{C}$ for 24 hours. The frozen solution was allowed to melt gradually at room temperature. A small amount of dichloroacetic acid (DCA) was added to produce a clear gel. A solution of good spinning quality was obtained by the addition of either ethylene chloride or diisopropyl ether. The viscosity of the spinning solution was estimated by the falling ball method and adjusted to around 100 poise by the addition of $99 \%$ formic acid. The glass apparatus imposed a limitation on the viscosity of the solutions. However, a better quality of fiber would be possible by applying higher concentration of chitin. The resulting viscous solution was filtered through a flannel under pressure and spun into the 1st coagulation bath through a platinum nozzle at a pressure of $0.4-1.3$ $\mathrm{kg} \mathrm{cm} \mathrm{cm}^{-2}$. The partly coagulated filaments were solidified in the 2nd coagulation bath and stretched continuously in water. The solvent composition of the spinning solution and spinning conditions are given in Table I. The spinning was carried out at room temperature, except in the case of the stretching bath. An outline of spinning apparatus was presented in a previous paper. ${ }^{3}$ The acetylchitin fiber, wound on a cassette, was immersed in boiling water for one hour to remove any trace of formic acid or DCA. After being washed in running water overnight, the fiber was air-dried.

The acetylchitin films were prepared as follows: (1) drying a cast acetylchitin solution on a glass plate at $40-50^{\circ} \mathrm{C}$, or (2) solidifying a cast solution in alcohol, and then drying by pressing it between papers at room temperature.

\section{Measurements of Fiber Properties}

The properties of the acetylchitin fibers were measured in a manner reported previously. ${ }^{2}$ The relative wet tenacity and the relative knot strength were calculated by the following equations.

Relative wet tenacity

$$
=\frac{\text { Wet tenacity }}{\text { Dry tenacity }\left(20^{\circ} \mathrm{C}, 65 \% \mathrm{RH}\right)} \times 100
$$

Table I. Spinning conditions for the fibers

\begin{tabular}{|c|c|c|c|c|c|c|c|c|c|}
\hline \multicolumn{2}{|c|}{ Sample number } & 1 & 2 & 3 & 4 & 5 & 6 & 7 & 8 \\
\hline \multicolumn{2}{|l|}{ Degree of acetylation } & 0 & 0.3 & 1.1 & 1.6 & 2.0 & $2.0^{\mathrm{a}}$ & 0 & 0.3 \\
\hline \multirow{2}{*}{ Spinning } & Solvent & FA:DCA & FA: EC & FA : DCA & $\mathrm{FA}: \mathrm{DCA}$ & FA: EC & FA: EC & FA : DCA & FA \\
\hline & $\mathrm{v} / \mathrm{v}$ & $92: 8$ & $2: 1$ & $75: 6$ & $12: 1$ & $2: 1$ & $2: 1$ & $92: 8$ & \\
\hline Condition & $\frac{\text { Concn }}{\%, w / v}$ & 4.0 & 4.2 & 6.1 & 3.9 & 13.3 & 13.3 & 3.0 & 4.2 \\
\hline \multicolumn{10}{|l|}{$\mathrm{kg} \mathrm{cm}^{-2}$} \\
\hline \multicolumn{2}{|c|}{$\begin{array}{l}\begin{array}{l}\text { Nozzle } \\
\text { Coagulation bath }\end{array} \quad \begin{array}{l}\text { 1st } \\
2 \mathrm{nd}\end{array} \\
\text { Stretching bath (water) }\end{array}$} & $60^{\circ} \mathrm{C}$ & $50 \%$ & $\begin{array}{l}\text { Pt, } 0.09 \mathrm{mr} \\
\text { Diisopr } \\
\text { Acetic acid }\end{array}$ & $\begin{array}{l}\phi 50 \text { Hole } \\
\text { pyl ether } \\
\text { ethanol (2 } \\
10^{\circ} \mathrm{C}\end{array}$ & $2: 5 \mathrm{v} / \mathrm{v})$ & & $\begin{array}{r}\text { Ethyl a } \\
\text { Etha } \\
60^{\circ}\end{array}$ & $\begin{array}{l}\text { setate } \\
\text { nol } \\
\text { C }\end{array}$ \\
\hline$\frac{\text { 1st Roller }}{\mathrm{m} \mathrm{min}^{-1}}$ & & 5.2 & 5.7 & 5.7 & 5.6 & 5.7 & 5.7 & 5.6 & 5.6 \\
\hline$\frac{\text { 2nd Roller }}{\mathrm{m} \mathrm{min}^{-1}}$ & & 5.8 & 6.5 & 7.5 & 7.7 & 8.2 & 8.2 & 7.3 & 7.3 \\
\hline Stretching ratio & & 1.10 & 1.14 & 1.32 & 1.38 & 1.44 & 1.44 & 1.30 & 1.30 \\
\hline
\end{tabular}

a Prepared by perchloric acid method. The others are by methanesulfonic acid method.

b Coagulated at room temperature.

Abbreviations: FA, 99\% formic acid; DCA, dichloroacetic acid; EC, ethylene chloride. 
Relative knot strength

$$
=\frac{\text { Knot strength }\left(20^{\circ} \mathrm{C}, 65 \% \mathrm{RH}\right)}{\text { Dry tenacity }\left(20^{\circ} \mathrm{C}, 65 \% \mathrm{RH}\right)} \times 100
$$

\section{Direct Acetylation of Chitin Fiber}

Direct acetylation was performed by using one of the following two methods: (1) $0.55 \mathrm{~g}$ of chitin fiber was treated with a $20 \%$ aqueous solution of sodium acetate for $12 \mathrm{~h}$ at room temperature and fiber was dried in vacuo afrer removal of the aqueous solution. The dried fiber was acetylated at $95^{\circ} \mathrm{C}$ for $24 \mathrm{~h}$ in acetic anhydride vapour under reduced pressure. (2) $0.55 \mathrm{~g}$ of chitin fiber was dipped into a perchloric acid-acetic anhydride mixture [ $4 \mathrm{ml}$ of acetic anhydride and $0.1 \mathrm{ml}$ of perchloric acid $(80 \%)$ ] at $0^{\circ} \mathrm{C}$ for $24 \mathrm{~h}$. The fiber was washed in ice-cold water, then with ethanol, and dried in vacuo.

\section{Staining of the Acetylchitin Fibers}

Three kinds of acidic dyes, Suminol Fast Brilliant Red S3B, Suminol Fast Yellow $R$ conc. and Suminol Fast Blue R, were used. The acetylchitin fibers were stained with a given dye solution $(3 \%$ of acetic acid, $1 \%$ of dye) for $90 \mathrm{~min}$ at $90^{\circ} \mathrm{C}$. The stained fiber was treated with a $0.5 \%$ soap solution containing $0.2 \%$ sodium sulfate at $60^{\circ} \mathrm{C}$ for $1 \mathrm{~h}$, washed with running water overnight and then airdried.

\section{$X$-Ray Diffraction Pattern}

$\mathrm{X}$-Ray diffraction patterns of the fibers were recorded with $\mathrm{Cu}-\mathrm{K}_{\alpha}$ radiation from a Toshiba $\mathrm{X}$ ray Generator ADX-401. Silicon powder was used as the standard for estimating the spacings.

\section{RESULTS AND DISCUSSION}

\section{Preparation of Spinning Solution}

The solubility of acetylchitin in $99 \%$ formic acid was found to depend on the degree of acetylation. Diacetylchitin dissolved completely in $99 \%$ formic acid up to a concentration of $20 \%$, with only stirring. However, a solution having good spinning quality was not produced until ethylene chloride or diisopropyl ether was added. On the other hand, repeated freezing and the addition of DCA were required to dissolve the 1.1 acetylchitin, even up to a concentration of $10 \%$.

\section{Preparation of Acetylchitin Fibers}

Diisopropyl ether was selected as the initial coagulant among several other poor solvents, such as dimethyl sulfoxide, dioxane, acetone, tetrahydrofuran, methyl ethyl ketone and ether. Also ethyl acetate could be used for spinning of the chitin fiber but partially melted filaments were obtained on the acetylchitin fiber as shown in Table II (denier).

\section{Direct Acetylation of Chitin Fiber}

Chitin fiber was acetylated directly by being immersed in a perchloric acid-acetic anhydride solution at $0^{\circ} \mathrm{C}$ for $24 \mathrm{~h}$ and being washed repeatedly in ice-cold water. It may be that the acetylation reaction proceeds from fiber surface, since the opaque fiber becomes clear from the surface. Prolonged reaction time or high temperature seems to make the acetylchitin fibers brittle. The degree of acetylation was estimated by elemental analysis as the 1.0 acetylation, although the reaction was heterogeneous. Anal. Calcd for $\mathrm{C}_{10} \mathrm{H}_{15} \mathrm{NO}_{6} \cdot 1 / 2 \quad \mathrm{H}_{2} \mathrm{O} ; \mathrm{C}, 47.24 \% ; \mathrm{H}, 6.30 \% ; \mathrm{N}$, $5.51 \%$. Found: C, $47.25 \%$; H, 6.18\% N , 5.38\%. Only 0.2 acetylation took place by the sodium acetate-acetic anhydride method (1).

\section{Properties of the Acetylchitin Fibers}

The general properties of variously acetylated chitin fibers are summarized in Table II. The relationship between yield stress $\left(\mathrm{g} \mathrm{d}^{-1}\right)$ and yield strain $(\%)$ at the breaking point of fibers is shown in Figure 1 at various degrees of acetylation under different conditions. Figure 1 suggests that the 1.1 acetylchitin fiber should have best quality of all the variously acetylated chitin fibers. The tenacity and elongation of acetylchitin fibers are plotted against the degree of acetylation under the different conditions in Figures 2 and 3. The fibers show maximum tenacity and elongation in the case of acetylation of 1.1. Also maximum knot strength was shown in the 1.1 acetylation as seen in Figure 4, though the relative knot strength decreases remarkably with an increase in the degree of acetylation. On comparing the 1.1 acetylchitin fiber with triacetyl- and diacetyl-cellulose fibers, it can be seen that their tenacities are reasonably close but that the degree of elongation and knot strength of the acetylated cellulose fibers are about twice those of acetylchitin fibers.

Relative wet tenacity has the tendency to increase 
S. Tokura, N. Nishi, O. Somorin, and J. NoGUCHI

Table II. Properties of chitin and acetylchitin fibers

\begin{tabular}{|c|c|c|c|c|c|c|c|c|c|}
\hline \multicolumn{2}{|c|}{ Sample number } & 1 & 2 & 3 & 4 & 5 & 6 & 7 & 8 \\
\hline \multicolumn{2}{|c|}{ Degree of acetylation } & 0 & 0.3 & 1.1 & 1.6 & 2.0 & $2.0^{\mathrm{a}}$ & 0 & 0.3 \\
\hline \multirow[t]{2}{*}{ Tenacity } & Dry $\left(20^{\circ} \mathrm{C}, 65 \% \mathrm{RH}\right)$ & 0.68 & 0.94 & 1.89 & 1.52 & 1.13 & 1.48 & 1.32 & 1.73 \\
\hline & Wet $\left(20^{\circ} \mathrm{C}, 100^{\circ} \mathrm{RH}\right)$ & 0.23 & 0.33 & 0.75 & 0.58 & 0.50 & 0.56 & 0.18 & 0.74 \\
\hline $\mathrm{g} \mathrm{d}^{-1}$ & Wet $\left(90^{\circ} \mathrm{C}, 100 \% \mathrm{RH}\right)$ & 0.23 & 0.37 & 0.75 & 0.65 & 0.43 & 0.39 & 0.18 & 0.73 \\
\hline \multirow[t]{2}{*}{ Elongation } & Dry $\left(20^{\circ} \mathrm{C}, \quad 65^{\circ} \% \mathrm{RH}\right)$ & 2.9 & 5.7 & 11.7 & 5.3 & 7.5 & 7.0 & 2.7 & 3.7 \\
\hline & Wet $\left(20^{\circ} \mathrm{C}, 100 \% \mathrm{RH}\right)$ & 10.8 & 13.7 & 22.7 & 12.9 & 14.1 & 15.4 & 7.8 & 15.6 \\
\hline$\%$ & Wet $\left(90^{\circ} \mathrm{C}, 100 \% \mathrm{RH}\right)$ & 13.0 & 15.2 & 22.1 & 14.4 & 15.9 & 20.6 & 7.1 & 15.7 \\
\hline \multirow[t]{2}{*}{ Young's modulus } & Dry $\left(20^{\circ} \mathrm{C}, 65 \% \mathrm{RH}\right)$ & 42.7 & 45.9 & 55.7 & 75.2 & 49.7 & 64.0 & 71.5 & 70.8 \\
\hline & Wet $\left(20^{\circ} \mathrm{C}, 100^{\circ} \% \mathrm{RH}\right)$ & 2.4 & 2.5 & 6.0 & 6.4 & 3.4 & 4.7 & 2.7 & 5.5 \\
\hline $\mathrm{g} \mathrm{d}^{-1}$ & Wet $\left(90^{\circ} \mathrm{C}, 100^{\circ} \% \mathrm{RH}\right)$ & 2.0 & 2.0 & 5.0 & 5.1 & 2.5 & 1.7 & 2.4 & 5.4 \\
\hline \multicolumn{2}{|c|}{ Knot strength } & & & & & & & & \\
\hline & & 0.45 & 0.44 & 0.64 & 0.39 & 0.14 & 0.31 & 0.45 & 0.41 \\
\hline \multicolumn{10}{|c|}{$\mathrm{g} \mathrm{d}^{-1}$} \\
\hline \multicolumn{2}{|c|}{ Density } & & & & & & & & \\
\hline \multirow{2}{*}{\multicolumn{10}{|c|}{$\mathrm{g} \mathrm{cm}^{-3}$}} \\
\hline & & & & & & & & & \\
\hline \multicolumn{2}{|c|}{ Moisture recovery } & & & & & & & & \\
\hline & 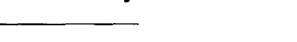 & 13.0 & 13.9 & 11.9 & 9.3 & 8.5 & 9.5 & 12.9 & 21.3 \\
\hline \multicolumn{10}{|c|}{$\%$} \\
\hline \multicolumn{2}{|c|}{ Denier } & & & & & & & & \\
\hline & & 3.2 & 3.6 & 4.0 & 4.3 & 12.5 & 13.1 & 25.5 & 50.1 \\
\hline \multicolumn{2}{|r|}{$\mathrm{d}$} & & & & & & & & \\
\hline
\end{tabular}

a Prepared by perchloric acid method. The others are by mechanesulfonic acid method.

slightly with an increase in the degree of acetylation as shown in Figure 5. This phenomenon seems to correspond to the reduction of moisture recovery of the fibers as shown in Table II.

However, the relative knot strength decreased with an increase in the degree of acetylation. This suggests that the flexibility of the molecule decreases with acetylation.

The dependence of Young's modulus on the degree of acetylation is shown in Figure 6 for various conditions. The maximum value is given at the 1.6 acetylation in the dry state. These values vary slightly in the wet state. The fairly higher Young's modulus values for acetylchitin fibers are closer to those obtained for rayon fiber than to those for acetate fiber.

In regard to the microscopic profiles of the acetylchitin fibers, the highest transparency was observed for the 1.1 acetylchitin fiber. A clear cross section could also be observed for acetylchitin fibers prepared with diisopropyl ether; This could not be observed for the diacetylchitin fiber (\#6, acetylated by methanesulfonic acid method).

The dyeability of acetylchitin fibers was similar to that of chitin fiber having little dependence on the degree of acetylation. The luster of the surface of acetylchitin fibers persisted even after staining. In a previous study, the dyeability of viscose rayon fibers mixed with chitin viscose depended simply on the chitin content. It is considered that acetylchitin may be useful for increasing the sensitivity of acetate fiber toward dyes, since there is no phase separation in the acetylchitin, acetylcellulose, and formic acid mixture.

In conclusion, it can be said that acetylchitin fibers have better tenacity and a higher degree of 
Acetylchitin Fibers

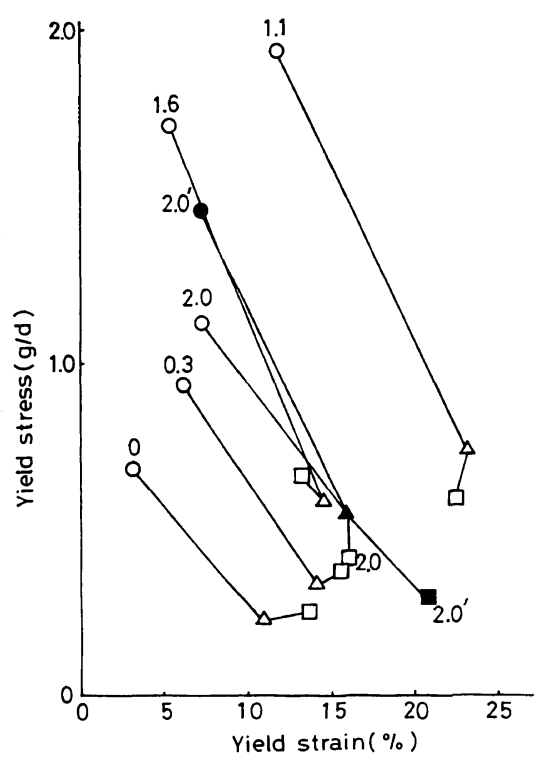

Figure 1. The yield stress and yield strain of acetylchitin fibers under different conditions: $-\mathrm{O}-$, at $20^{\circ} \mathrm{C}$, $65 \% \mathrm{RH} ;-\triangle-$, at $20^{\circ} \mathrm{C}, 100 \% \mathrm{RH} ;-\square-$, at $90^{\circ} \mathrm{C}$, $100 \% \mathrm{RH} ;-\mathbf{-}-,-\mathbf{\Delta}-,-\mathbf{-}-$, diacetylchitin prepared by perchloric-acid method.

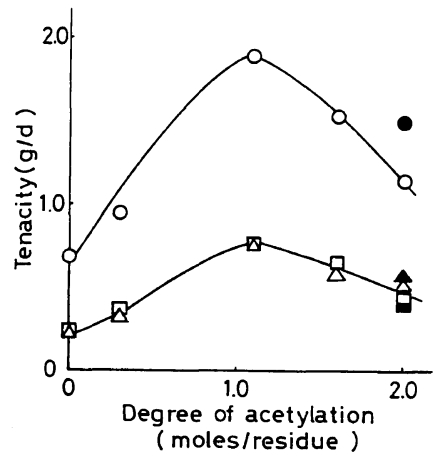

Figure 2. The relationship between tenacity and degree of acetylation under different conditions. - $\mathrm{O}-$, at $20{ }^{\circ} \mathrm{C}, 65 \% \mathrm{RH} ;-\triangle-$, at $20^{\circ} \mathrm{C}, 100 \% \mathrm{RH} ;-\square-$ $90{ }^{\circ} \mathrm{C}, 100 \%$ RH. Closed markers are diacetylchitin prepared by the perchloric-acid method.

elongation and knot strength than chitin fibers. These advantages should enhance the practical usefulness of chitin in spite of its poor solubility in organic solvents and lack of reactivity toward chemical reagents.

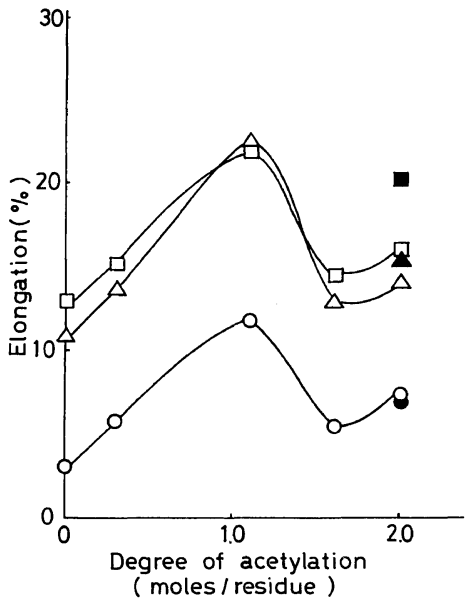

Figure 3. The relationship between elongation and degree of acetylation under different conditions: $-\mathrm{O}-$, at $20^{\circ} \mathrm{C}, 65 \% \mathrm{RH} ;-\triangle-$, at $20^{\circ} \mathrm{C}, 100 \% \mathrm{RH} ;-\square-$, at $90^{\circ} \mathrm{C}, 100 \% \mathrm{RH}$. Closed markers are diacetylchitin prepared by the perchloric-acid method.

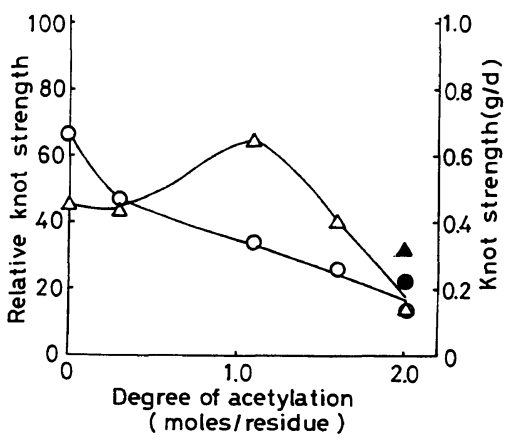

Figure 4. The dependency of the relative knot strength and knot strength on the degree of acetylation at $20^{\circ} \mathrm{C}$ $65 \%$ RH: $-\mathrm{O}-$, relative knot strength; $-\triangle-$, knot strength. Closed markers are diacetylchitin prepared by the perchloric-acid method.

\section{$X$-Ray Diffraction Pattern}

The determination of molecular orientation by $\mathrm{X}$ ray diffraction pattern was possible for 1.1 acetylchitin fiber but not for diacetylchitin fiber. The spacings of the 1.1 acetylchitin fiber were identical with those of regenerated chitin fibers. ${ }^{2}$ Diacetylchitin fiber seems to be mostly amorphous even though it has a higher stretching ratio as shown in Table I. 


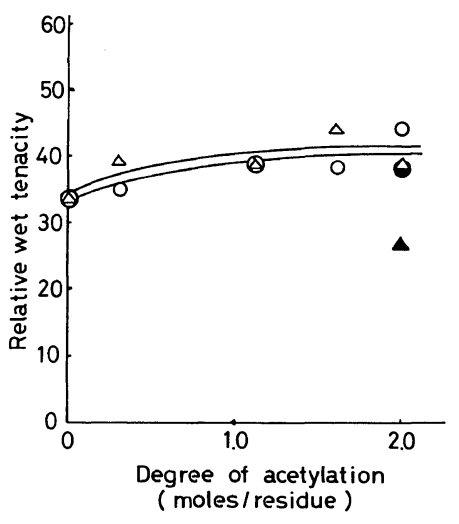

Figure 5. The dependency of relative wet tenacity on the degree of acetylation under different conditions. - - - at $20^{\circ} \mathrm{C}, 100 \% \mathrm{RH} ;-\triangle$ - at $90^{\circ} \mathrm{C}, 100 \% \mathrm{RH}$. Closed marker are diacetylchitin prepared by the perchloric-acid method.

\section{Acetylchitin Film}

Films of variously acetylated chitin were prepared by two methods and it was shown by scanning electron microscopic observation that a great many pin holes result from the vaporization of formic acid in the preparation method (1). However, the films prepared by the wet method (2) manifested a surface affording a softer feeling to the touch than that of chitin film prepared in a similar manner. The properties of the acetylchitin films are being given further investigation.

Acknowledgements. The authors should like to express their appreciation to Mr. H. Shiota of our laboratory for his technical assistance in the spinning. Also we are grareful to the Mitsubishi Rayon Co. Ltd. and Kyowa Yushi Co. Ltd. for their support.

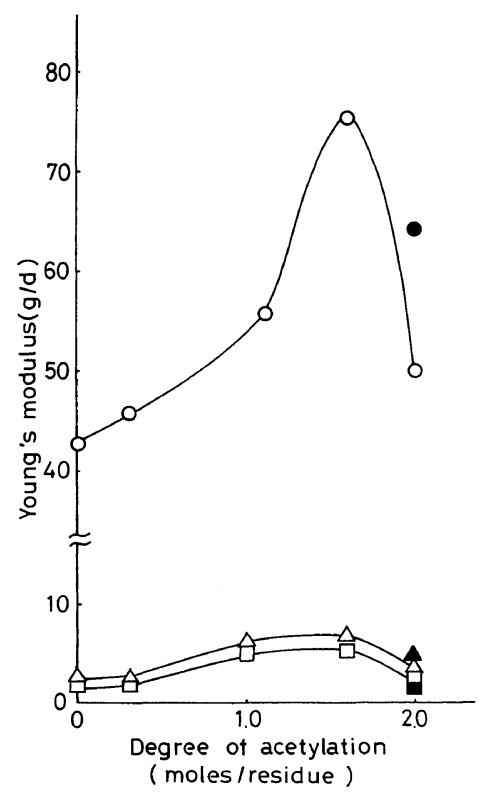

Figure 6. The dependency of Young's modulus on the degree of acetylation under different conditions: - $\mathrm{O}$ - at $20^{\circ} \mathrm{C}, 65 \% \mathrm{RH} ;-\triangle-$, at $20^{\circ} \mathrm{C}, 100 \% \mathrm{RH} ;-\square-$, at $90^{\circ} \mathrm{C}$, $100 \%$ RH. Closed marker are diacetylchitin preparared by the perchloric-acid method.

\section{REFERENCES}

1. J. Noguchi, O. Wada, H. Seo, S. Tokura, and N. Nishi, Kobunshi Kagaku, 30, 320 (1973).

2. S. Tokura, N. Nishi, and J. Noguchi, Polym. J., 11, 781 (1979).

3. J. Noguchi, S. Tokura, and N. Nishi, "Proceedings of The 1st International Conference on Chitin/ Chitosan," R. A. A. Muzzarelli and E. R. Pariser, Ed., 1978, p 315.

4. N. Nishi, J. Noguchi, S. Tokura, and H. Shiota, Polym. J., 11, 27 (1979). 